\title{
Article \\ Effect of Cultural Distinctiveness and Perception of Digital Advertising Appeals on Online Purchase Intention of Clothing Brands: Moderation of Gender Egalitarianism
}

\author{
Syed Hassan Raza ${ }^{1}$ (D) and Umer Zaman ${ }^{2, *(D)}$ \\ 1 Department of Communication Studies, Bahauddin Zakariya University, Multan 66000, Pakistan; \\ hassansherazi@bzu.edu.pk \\ 2 Endicott College of International Studies, Woosong University, Daejeon 34606, Korea \\ * Correspondence: umerzaman@endicott.ac.kr
}

check for updates

Citation: Raza, S.H.; Zaman, U. Effect of Cultural Distinctiveness and Perception of Digital Advertising

Appeals on Online Purchase Intention of Clothing Brands: Moderation of Gender Egalitarianism. Information 2021, 12, 72.

https://doi.org/10.3390/ info12020072

Academic Editors: Umair Akram, Jiayin Qi and Nada Trunk Širca Received: 31 December 2020 Accepted: 4 February 2021 Published: 7 February 2021

Publisher's Note: MDPI stays neutral with regard to jurisdictional claims in published maps and institutional affiliations.

Copyright: (c) 2021 by the authors. Licensee MDPI, Basel, Switzerland. This article is an open access article distributed under the terms and conditions of the Creative Commons Attribution (CC BY) license (https:/ / creativecommons.org/licenses/by/ $4.0 /)$.

\begin{abstract}
Digital advertising has been frequently used for the promotion of e-commerce among individuals. However, little is known about the function of cultural factors that can outline the effectiveness of digital advertising practices to alter attitude and consumer behavior toward clothing brands. This research examines how norm-congruent attitudes toward digital advertising (hereafter ADA) may operate as a process variable that mediates the relationship between perception about digital advertising (hereafter PDA) and online purchase intention of fashion brands (hereafter OPI). We propose a gender egalitarianism (hereafter GE)-moderated mediation model whereby ADA mediates the relationships between PDA and OPI in two culturally diverse nations: Malaysia and Pakistan. The model was tested by using 2 (GE appeal: present vs. absent) $\times 2$ (nation: Pakistan vs. Malaysia) $\times 2$ (no exposure to ads/exposure to ads) experimental design with data obtained from a sample of 260. Findings show that there is a significant difference in the relationship between PDA and OPI that is mediated by the attitude in both nations. However, the mediation implication of the attitude is significantly dependent on the interaction of the GE. In this way, the study provides some practical recommendations for the marketers by highlighting the salient advertising features that may be more useful in both nations.
\end{abstract}

Keywords: consumer behavior; digital advertising; attitude; purchase intention; gender egalitarianism; cross-cultural; marketing communication

\section{Introduction}

Tailoring advertising campaigns to local culture now has more leeway for brands [1]. This regionalization approach has its useful facets because cultural sensitivities vary from culture to culture [2,3]. For instance, the local advertising campaigns could become culturespecific. Individuals have diverse perceptions of what advertisements are for from place to place; for this reason, making advertising local could permit advertisers to more befittingly choose what pitches would be more efficacious $[4,5]$. The question of standardized vs. localized advertising has created a constant debate over the past decade because of the deficiency of exhaustive empirical evidence in support of the localized approach [6].

Furthermore, in the recent scenario wherein the rapid growth in the internet usage across different parts of the world has developed the World Wide Web as a populous advertising medium [7,8], The Interactive Advertising Bureau stated US digital advertising revenue reached USD 125 billion in 2019 with a 16\% annual increase, indicating the prominence of digital advertising [9]. However, among all sectors of e-commerce, fashion and clothing brands demonstrated steady growth in revenues through digital advertising [10]. Given that advertisers are now reaching out to new e-marketplaces to capitalize on digital advertising, the requisite to understand the cultural dynamics are crucial for them [4]. The use of displaying the women models is quite common practice for clothing 
brands and at times disapproved by consumers owing to the culturally mismatched depiction of women [10]. From the standpoint of advertisers, gender is a prime segmentation variable in evolving digital advertising strategies [11] and in terms of detecting cultural patterns $[12,13]$. In addition, gender depictions have conceivable effects on the corporate image [14] and the purchasing patterns of consumers [15]. The literature has witnessed a plethora of research limited to the gender-role depictions in advertising $[15,16]$. Likewise, the overwhelming body of available work [17] in advertising focuses on standardization and advertising strategy standpoints without an explicit deliberation of the consumer response on egalitarianism norms from different Asian or Muslim markets.

In Muslim markets such as Pakistan and Malaysia, it is imperious to acknowledge that some dichotomies between the reality and rhetoric of advertised depiction of the gender role may exist guided by egalitarianism norms and alter their attitude [18-20]. To this end, the representation of gender in digital advertising may result in different outcomes contingent on egalitarian norms of the market in question [21]. Ergo, it is imperative to consider cultural constructs to delineate how several societies evaluate the advertisement by relying on cultural manifested ideas related to gender equality. To uncover these patterns, past research on gender-role depictions have repeatedly pointed to the significant role of cultural manifestations and widely applied Hofstede's masculinity/femininity dimension in advertising research [22]. However, most of the studies found no association between the masculinity index and gender depictions [23], or a few studies have reported mixed results [16].

In contrast, the global leadership and organizational behavior effectiveness (hereafter GLOBE) dimension of gender egalitarianism (GE) albeit is different in terms of its operationalization and may add new information in the literature in understanding the dominant values that drive the perception of individuals in the response of gender role depicted in advertisements [24,25]. Notwithstanding the call to apply GLOBE's GE dimension [26,27], only a few content analyses [21,28] and experimental studies [12] to date have employed it in advertising research and have found its association with gender portrayals. As mentioned, the purpose of this study is to examine the applicability of the localized advertising approach by investigating the heterogeneity assumption made by those encouraging the use of local cultural context while designing digital advertisements.

Certainly, drawing on similarity-attraction paradigm (hereafter SAP) theory and GLOBE, we also expect that the norm congruence-based predispositions of the Pakistani and Malaysian individuals may also work similarly in interpreting digital advertising to determine the online purchase intention of clothing brands' outcome. Owing to the context of e-commerce, research has chosen the most popular e-commerce category of the clothing brand [29]. Furthermore, clothing brands are commonly advertised on digital platforms with the intent to pursue online shopping behavior [30]. The clothing category is also suitable because Muslim consumers typically decide on the clothing by evaluating social and cultural factors product categories [31]. Therefore, the direction and strength of the intention in the reply of digital advertising are also dependent on the agreement of the individual's attitude, which is dependent on the cultural interpretation of appeal that may differ from culture to culture. However, the intensity may be different, as both nations have different interpretations of the norm congruence grounded in the cultural differences, which are in line with the notions of cultural dimensions [32]. For example, the cultural framework of GLOBE) [33] placed Malaysia on a low score of 36, and it indicates they are sensitive toward societal factors such as norms and advertising leverages may route through attitude. Hence, by integrating postulations of cultural indices of GE, consumer behavior theories such as the theory of planned behavior (hereafter TPB) and SAP [34] and the advertising influence model [35] may advance understanding that digital advertising effectiveness depends on the distinctiveness of consumers across cultures. In this regard, the study addresses this void by assessing consumer perceptions of digital advertisements in two distinct Asian Muslim nations and proposes a GE-moderated mediation model of attitude whereby ADA mediates the relationships between PDA and OPI. Ergo, the 
objective of this research is to investigate if Asia can be profound to the societal values adaptation in digital advertisement appeals. By concentrating on the responses of the individuals from two diverse Asian cultures (i.e., Pakistan and Malaysia), this research investigates the effectiveness of adaptation strategies in digital advertising within the Asian nations.

\section{Literature Review}

\subsection{Research Gap and Theoretical Underpinnings}

Past studies have examined reported varied findings and remain inconclusive about the efficacy of advertising adaptation or standardization strategy [26,36]. Both paradigms have utilized several cultural models such as Hofstede's to understand the effectiveness of advertising [37]. To do so, the theoretical paradigm is a contrast between populous cultural orientations and advertising strategy practices effectiveness across the cultures. This to validate the notion of effectiveness of the adopted strategy of the advertising based on the value congruity. The value congruity is a psychological and rationalized evaluation that an individual makes regarding the convergence or divergence of the advertised brand based on their own established cultural values [2]. In this standard, the adapted advertisements demonstrate attributes deciphering a sense that corresponds with a given cultural orientation [38]. Past theory SAP assumed that the advertising adaptation by incorporating particular cultural norm appeals such as GE can stimulate favorable responses among customers. They sense conviction and attraction toward those stimuli that are more culturally congruent. Likewise, the GLOBE model suggested that cultural values serve as the locus points and people make decisions based on the perceived similarity of the behavior in question [39]. In verily, these theories affirmed that the congruency of ad appeals (verbal or non-verbal cues) are expected to cause a consumer to be attracted to culturally convergent advertising, leading toward self-affirmation [40]. Additionally, these culturally convergent ad appeals are expected to be trusted as socially accepted concerning the adoption of the advertised product or brand as liked. Scholars noted that SAP advocates that a high congruity or adaption strategy of advertising undertakings is expected to induce one's perceptions of correspondence and heighten the chance of engendering affirmative reactions toward the advertised product [41]. Generally, in designing digital advertising, factors such as norm congruence must be critically analyzed to avoid some kind of conflicting situations that may arise in the mind of the individuals while interpreting its meanings in their cultural perspectives.

The gap underpinned in this research is the extent to which GE is pertinent to the fashion industry in the generation of advertising appeals designed to attract consumers across culture. The use of GLOBE's GE cultural dimensions addressed the question of whether the use of societal measures known as the onion approach is more effective than the previously used cultural models such as Hofstede's, which presented individuallevel measurements to tap cultural variation. There are two facets of cultural variables that must be well thought out in advertising research. First, is the study interested in learning about the desirable (what people should do) or the desired (what people want to do) [40,42]? Usually, the answers to the questions of what an individual does and what one thinks should be done are inversely correlated. This is the origin of the fundamental theoretic discrepancy among the most popular nation culture models by Hofstede and GLOBE. Hofstede dimensions are based on the self-rating of the individual measure of the desired (i.e., Value). Conversely, GLOBE dimensions measure the norms that echo the desirable [43]. The GLOBE defined GE as "the degree to which a society minimizes gender role differences and women would be afforded the same opportunities as men within that particular society" [44] (p. 30). In this way, the GLOBE framework provides instruments to tap individual perceptions based on their observations about the characteristics of the relationship between the advertising verbal and non-verbal cues and cultural values. This research proposed a novel model (see Figure 1) drawing on the GLOBE dimension of GE to explain for the first time how the portrayal of gender roles in a fashion-related 
clothing brand's ad associates to the evaluation of adaption advertising strategy and brand evaluation. To validate the applicability of SAP theory, this is the first study that examined the effectiveness of cultural self-congruity cross-culturally in two Asian nations that are highly dissimilar in terms of the extent of GE. In sum, the study considers the normcentered approach to get an evaluation of the appeal stimulus to reinforce the importance of considering norm-based predisposition on the prediction of intention. Further sections will delineate the underpinned assumptions in detail.

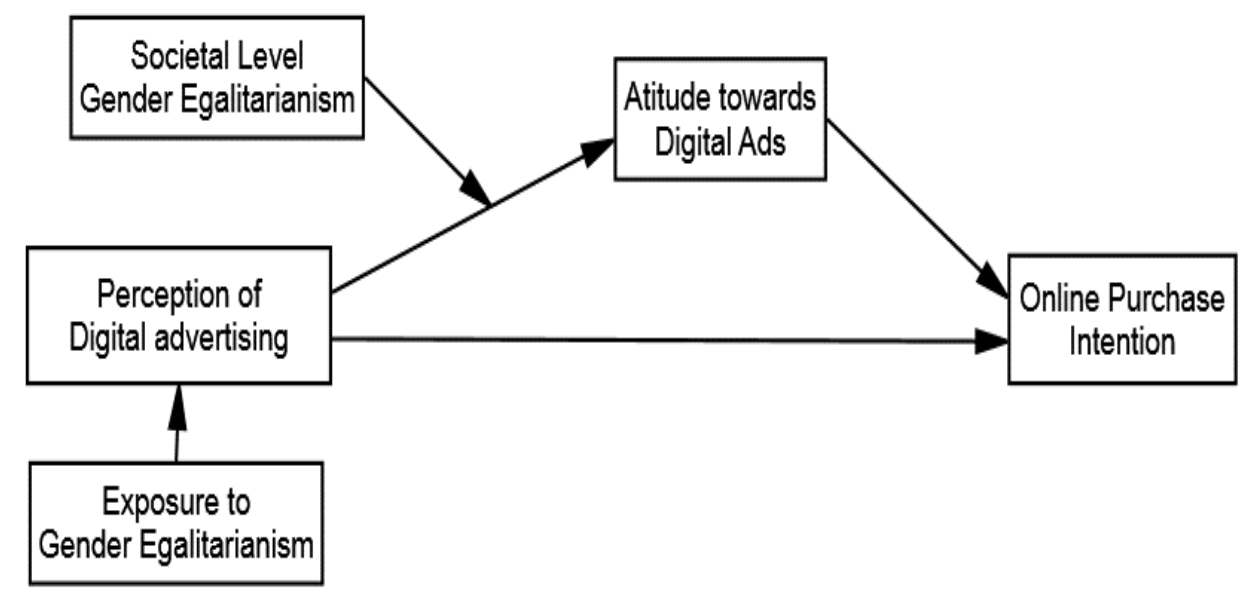

Figure 1. Theoretical framework.

\subsection{Pakistan and Malaysia: Two Distinct Cultures}

Malaysian culture is a multicultural as well as multi-religious society. Within Malaysian society, there is a Malay culture, a Chinese culture, an Indian culture, and a Eurasian culture, along with other cultures. Malay (natives) are the main ethnic group in Malaysia and shape the cultural norms of society [45]. Culturally, Malaysia is distinct from Pakistan based on several cultural orientations such as GE, humane, and future orientated [46]. On the other hand, Pakistani culture is culturally a more collectivistic and religious society [47]. Within Pakistani culture, there is a Punjabi culture, a Sindhi culture, a Balochi culture, a Pakhton culture, along with several small ethnic cultures [48]. This demographic segmentation of Pakistan is distinct from the Malaysian culture. In verily, Pakistan is a distinct culture largely based on its ethnic attributes, unlike Malaysia, where religious differences also shape the cultural diversity of the society. Moreover, scholars described Pakistani culture as amongst those with the most collectivistic features. Past studies also found that Pakistani individuals frequently maintain strong cultural orientations that impact their behavior. Limited studies have been conducted on Pakistani consumers that found that individuals' preferences are highly influenced by cultural factors [49]. In the context of advertising, culturally, Malaysian consumers showed modest characteristics [50]. However, individuals in collectivistic societies such as Pakistan usually uphold codes of beliefs and norms that influence their behavioral patterns. Ergo, Pakistanis may resist norm-deviating advertising appeals, and individual preferences may determine by cultural sensitivities more than Malaysians.

\subsection{Effect of Digital Advertising on Online Purchase Intention}

Digital advertising is becoming a more common medium owing to the popularity of the online purchasing phenomenon [51]. The marketers are utilizing the e-commerce facilities available now owing to the growth of internet users [7]. Thus, the display and design of generating effective digital advertising are pertinent for the marketers to persuade their potential customers [4,52]. Digital advertising appeals refers to the features of advertising comprised of a message and the display of digital advertising to manipulate the positive influence on the individual's perception $[8,53]$. Nowadays, appeals are used in digital ad- 
vertising to motivate individuals to take behavior-related actions [54]. Digital advertising comprises elements such as the message, specifically designed to get a positive assessment of the online advertised products/services [55]. For instance, to motivate the individuals', advertisers incorporate emotional or rationale appeals in the message and display of digital advertisements. However, the motivation of the individual is not solely dependent on the aspirations of the advertisers. Up to this point, digital advertising literature is replete with only conceptual assessments of the appropriateness of localized advertising strategies in the international marketplace [6]. In doing so, the individual-level dimensions such as those of Hofstede have been used in advertising research, individualism in advertising, mobile advertising [56], digital advertising [57], nudity in advertising [57], or the use of appeals in advertising [58] to understand the possible effects of cultural sensitivities on attitude or intention.

Purchase intention is defined as the approved condition of the individuals to take behavioral actions dependent on the personal and social influences alongside the positive predisposition of the individuals [59]. Scholars clarified that the intention is a consequence of the perception of an individual to act directed by the normative approval and personal influences. The literature also supported the consideration of the cultural influence to examine the intention $[3,60]$. However, individuals also consider how others think about individuals' choices in terms of the product, which can determine the actual intention. Likewise, research has recommended considering other factors alongside normative influences involved to determine the intention, such as the personal preferences of individuals to purchase. For example, the product features (i.e., product type, affordability) are also important to consider measuring the purchase intention. Confining a study to one aspect may give misleading information about the actual intention [61]. Therefore, it is critical to clarify the normative influence that personal likeness in terms of product features has on motivating individuals to choose a product such as clothing.

Past theories have identified attitude as the predictor of purchase intention [61]. However, recent studies have also indicated some factors to improve the intention, such as persuasive messages. It suggests that there is an underlying mechanism role of attitude in defining the purchase intention with other unexplored factors. To improve the productivity of attitude, studies have suggested determining the antecedent of the attitude, which remains minimal. Moreover, some studies explained factors such as information seeking and clarified that attitude does not solely predict the intention [62]. In the context of the TPB communication, scholars argued that digital advertising with the underlying mechanism of attitude could be examined due to its persuasive nature. This is in line with the recommendation to consider such persuasions and may serve as a significant factor to improve the prediction of the intention. We expect that Pakistanis also positively relate the digital advertising to the intention and hypothesized the following:

Hypothesis 1a (H1a). Perception of digital advertising PDA relates positively to OPI among the Pakistanis.

Moreover, we expect that Malaysian individuals also perceive the effect of digital advertising similarly and online purchase intention for a clothing brand may relate to the advertising features directly. Thus, we hypothesized the following:

Hypothesis $\mathbf{1 b}(\mathbf{H 1 b})$. Perception of digital advertising PDA relates positively to OPI among the Malaysians.

\subsection{Moderated Mediation of the Attitude toward Digital Advertising and Cultural Distinctiveness}

We expect that the OPI outcome in response to digital advertising will be routed through the attitude process based on several reasons. For example, previous literature explained that advertising is persuasive, and it affects the perception of the individual by affecting its attitude. Digital advertising can function to persuade and convince individuals to change their attitudes [63]. Hence, digital advertising features may work 
as a way of making individuals aware of the advertised product/service with a motive of attitude change. Attitude change is based on the notion that digital advertising improves the chances of recognition, affective, and rational evaluation of the advertised product/service [64]. Previous models such as the hierarchy of effects model reinforced that digital advertising is closely linked with attitude $[65,66]$. However, the attitude is based on the individual's evaluation of digital advertising in the context of their prior understanding learned from national culture. The meanings of the advertising message can be perceived differently culturally [35].

However, in every nation, the effect of the attitude congruence with digital advertising may not be similar based on their different interpretations and may result in dissimilar OPI outcomes. The researchers noted that the effect of digital advertising relies on the extent to which it is congruent with norms as an individual's attitude is relevant to it [67]. Furthermore, the Hofstede model ranked Pakistan low (14) on individualism, which suggests that Pakistanis as a collectivist society are more dependent on societal rules [68]. Likewise, Malaysians are also low (26) on individualism. Based on the GLOBE dimension of the "in-group collectivism", Malaysia is also high (5.51) (see House et al., (2004, p. 469)), which indicates that norm congruence is important for the determination of the attitude among Malaysians.

The literature opined that the attitude depends on the extent to which elements of digital advertising are consistent with the norms and other predictors such as information, etc. [69]. Similarly, the prediction of the individual's intention is expected to be positive in case of the positive interpretation of the appeal and which leads toward the positive attitude. Hence, if the digital advertising features are positively evaluated by an individual as the result of their congruence with norms, it is expected to show a positive OPI. Our expectations about the forecast of the OPI depend on the ADA and PDA link. The OPI would go in a positive direction if the digital advertising appeal is perceived positively based on norm congruence interpretation of the individuals about the attitude.

For this scenario, the features employed in digital advertising in the form of message and display would be a crucial consideration for the individuals. If these features were found to be norm congruent by the individuals, the result would be a positive ADA. In this situation, advertising features norm similarity would lead toward the positive intention. In an alternative scenario, if digital advertising is found to be not like the norms, results would be in the opposite direction. The interpretation of such advertising features would be negative, which may result in a negative attitude that leads to negative OPI. Lastly, in both scenarios, the attitude remains the crucial factor, as we expect that it holds the fundamental implications to forecast OPI. However, the direction of ADA implications depends on the perception of individuals about congruent or incongruent norms in the case of clothing brands. Our expectation is in line with a theoretical assumption of TPB: attitude is the most significant predictor of intention. Finally, our view is in line with cultural models that also reported that Malaysia and Pakistan cultures are substantially dissimilar in numerous dimensions. For example, similar to many other dimensions, Pakistan scored high with 70 on the uncertainty avoidance index compared with Malaysia's 36. However, in Malaysian society, GE is more regarded than in Pakistani society. To this end, individuals who belong to nations that ranked higher on GE may appreciate the depiction of women in gender equality characters. In comparison, Pakistanis may have less positive PDA than Malaysians, and we hypothesized the following:

Hypothesis 2a (H2a). Digital advertising PDA among the Pakistanis relates weakly (less positive) to OPI through the mediating effect of attitude toward digital advertising (ADA).

Hypothesis $\mathbf{2 b}(\mathbf{H} 2 \mathbf{b})$. Digital advertising PDA among the Malaysians relates positively to OPI through the mediating effect of attitude toward digital advertising (ADA). 


\subsection{Moderating Factor of Gender Egalitarianism}

A plethora of literature affirmed that the congruence of advertisement cues with national culture could intensify the effect of digital advertising through improved attitude. In the case of an advertisement, congruence with cultural norms can lead toward a positive attitude [70]. Second, individuals from different cultures are also expected to have different patterns of response [71]. Therefore, Malaysians and Pakistani individuals are expected to have different attitudes and intentions based on interpretation of the digital advertising message and display. The literature also suggests that Pakistanis are expected to interpret digital advertising based on norm congruence rooted in attitude. Several studies used the masculinity/femininity dimension of the Hofstede model in a cross-cultural study. These studies found that it significantly influences the advertising effects; however, the tendency of influence was different in the two nations. In advertising, GLOBE GE has been rarely studied; only two studies in the past employed this construct. For instance, studies [24] have tested the cultural models for gender stereotyping in a content analysis of TV ads from 13 countries. Another content analysis was conducted [21] from four countries that coded the GE ads featuring women in a professional work situation and found significant discrepancy across countries. Only one empirical study was conducted in the context of advertising to understand how it interacts with digital advertising to strengthen or deepen its effects [35].

Thus, the GE interactional effects with digital advertising may further define the direction and strength of mediation of the ADA as it depends on the cultural assessment of the women's depiction in the advertisement. This is in line with the notion of the GE presented by the GLOBE model [60], in which members of a society use their cultural standpoint in defining the women's position and what it should be. Therefore, it may reflect the same tendency in the case of their attitude toward the advertised global product, which in turn affects their intention. Pakistanis are very sensitive toward the depiction of women in advertisements, and as a member of a male-dominated society, they may negatively assess the digital advertisements showing the GE; thus, the following are hypothesized:

Hypothesis 3a (H3a). Gender egalitarianism would negatively moderate the ADA and PDA relationship among the Pakistanis, and ADA would be decreased.

Societies such as Malaysia that are high on this dimension have more tolerance regarding women's equality [72]. However, the Malaysians are dissimilar in perceived gender roles and ranked higher on GE. Assumedly, Malaysians may have tolerance toward digital advertisements depicting women in equal status or decision-making roles. Thus, it is expected that this culturally learned belief about GE may result in a positive ADA, which may result in an improved OPI, and we hypothesized that:

Hypothesis $\mathbf{3 b} \mathbf{b} \mathbf{H} \mathbf{3 b})$. Gender egalitarianism would positively moderate the ADA and PDA relationship among the Malaysians, and ADA would be increased.

\section{Materials and Methods}

For this experiment, $(2 \times 2 \times 2)$ within and between-subject (in total, $\mathrm{N}=260)$ data were collected from the adults from two countries: Malaysia and Pakistan. The participants were invited to the research facilities in both countries from several academic faculties including in-class announcements, campus flyers, postings in campus social media groups, and disseminating information to the student associations. The participants who agreed to participate were briefed and requested to sign a consent form before the proceeding. There are two levels of three factors involved in this research: GE appeal (present vs. absence), exposure (no exposure to ads pre-test vs. exposure to ads post-test), and country (Pakistan vs. Malaysia).

Overall, 130 participants from Pakistan and Malaysia $(n=260)$ were repeatedly measured for the $(2 \times 2 \times 2)$ factorial design GE appeal (present vs. absence), exposure 
(no exposure to ads pre-test vs. exposure to ads post-test), and country (Pakistan vs. Malaysia). The recommended sample size for an experimental group is 30; therefore, the present study ample size is far above the recommended threshold. To avoid response biases, equal representation of male and female were chosen in the sample. The sample was also diverse in terms of ethnic representation. The Pakistani sample was comprised of almost 32\% Punjabis, 39\% Saraiki, 14\% Makhtoons, 9\% Balochis, and 6\% other ethnic groups. The Malaysian sample was comprised of almost 57\% Malayas, $24 \%$ Chinese, $11 \%$ Indians, and $8 \%$ other ethnic groups. In the initial phase, the participants were requested to fill a designed questionnaire based on the instruments adopted for the four variables PDA, ADA, GE, and OPI; participants were not exposed to any stimuli. Afterwards, the same participants were invited to the research facility and were again measured; each group consisted of $n=130$. This time, participants were exposed to the stimuli (digital advertisements). There was one separate digital advertisement for each country (ad showing high GE), and the participants completed the questionnaire to evaluate the digital advertising PDA, ADA, GE, and OPI. The same procedure was adopted in both countries (Pakistan and Malaysia). The factor $(2 \times 2 \times 2)$ design with the repeated measure is a useful procedure to decrease the possible threats to internal validity.

\subsection{Instrumentation}

\subsubsection{Ad Stimuli}

The two clothing brand digital advertisements were used to appraise the manipulation of the advertisement's stimulus (showing high GE). We selected four clothing brand advertisements in line with the desired characteristics of digital advertising: (1) message, (2) display, and (3) GE. To put it simply, the selected ad stimuli depicted women in decision-making roles in the ad content (message and display). Afterwards, a content validation procedure was adopted to ensure that the features of the selected advertisements fully represented the level GE (Malaysian and Pakistani norms) [73]. These four chosen advertisements were sent out accompanying all four PDA, ADA, GE, and OPI construct details and items to the ten academicians (five from each country) as well as ten advertising practitioners (five from each country) who specialized in marketing products in Pakistan and Malaysia. They were requested to suggest the most appropriate digital advertisements in the context of Pakistan and Malaysia. We selected the two digital advertisement stimuli (one for each country) of a foreign brand based on the recommendations of the experts. The authors conducted two pilot tests with 20 Pakistani students and 20 Malaysian students. The pilot tests ensured that the experimental procedures and ad stimuli were well communicated and understood.

\subsubsection{Measurements}

The PDA was measured by 3 items on a seven-point scale $(1=$ strongly disagree to 7 = strongly agree). These items were adapted from the scale presented in the literature [74] to tap the perceived value of an advertisement. The items to measure PDA were as follows: "(1) This digital advertising of this clothing brand is valuable because equality exists between the sexes, (2) The differences in the treatment of males vs. females have been avoided in this digital advertising; and (3) The digital advertising of this clothing brand is useful".

The ADA was measured through a 3-item semantic differential scale adopted from past literature [75]. The participants were asked to rate the digital advertisement anchoring on seven points after reading the following statement: "Please describe your overall feelings about the clothing brand described in the ad you just read". Digital advertisement is ( 7 = extremely good, 1 = extremely bad), $(7$ = extremely favorable, 1 = extremely unfavorable), and ( 7 = extremely appealing, 1 = extremely unappealing).

The OPI was measured by using 4 items on a seven-point scale ( 1 = strongly disagree to $7=$ strongly agree). The scale is a combination of the items on the two crucial features of the intention, purchase, and social influences [76]. The items were as follows: (1) "I will 
intend to buy this clothing brand presented in the digital ad", (2) "I have high purchase interest toward the clothing brand presented in the digital ad", (3) "I will intend to buy this clothing brand owing to its acceptance in my culture", and (4) "I intend to purchase this clothing brand because I will feel comfortable in social gatherings after wearing this dress".

The GE was measured through the 7 items on the seven-point scale $(1=$ strongly disagree to $7=$ strongly agree) adapted from the original work of the GLOBE project and re-worded [32]. The items for GE were measured on fellow items: (1) "In my society, people like the advertisements, which show that the boys are encouraged more than girls", $(2)$ "In my society, people avoid advertisements depicting males and females differently", (3) "In my society, people like advertisements depicting males and females as equals", (4) "Advertisements should minimize gender role differences", (5) "Advertisements avoid depicting typically male vs. female roles", (6) "Advertisements must treat males and females equally in the workplace", (7) "I should avoid watching advertisements in which females have no role in making decisions."

\section{Results}

Before the hypothesis testing, the separate descriptive analysis was conducted in two countries and both groups (Malaysia and Pakistan) comprising the sample ( $\mathrm{n}=260)$, while individually, each group contained half that number $(n=130)$. Firstly, the data were screened, and a normality test was conducted. The data were found within the standard cutoff values of the skewness and kurtosis for all four variables in all four groups, as illustrates in Table 1. In addition, the graphics review revealed some outliers and was removed to attain the normal distribution. To proceed with the inferential and validity analysis, the total sample $((n=210)$, with each group $(n=105))$ was retained.

Table 1. Experimental group (two countries): mean, standard deviation, and correlation.

\begin{tabular}{|c|c|c|c|c|c|c|c|c|c|c|c|c|}
\hline \multirow[b]{2}{*}{ Variables } & \multicolumn{2}{|c|}{$\mathbf{M}$} & \multicolumn{2}{|c|}{ SD } & \multirow{2}{*}{$\begin{array}{c}\text { PDA } \\
\text { Pak }\end{array}$} & \multirow{2}{*}{$\frac{\text { ADA }}{\text { Pak }}$} & \multirow{2}{*}{$\begin{array}{c}\text { OPI } \\
\text { Pak }\end{array}$} & \multirow[t]{2}{*}{ GE } & \multirow{2}{*}{$\begin{array}{c}\text { PDA } \\
\text { Mal }\end{array}$} & \multirow{2}{*}{$\begin{array}{c}\text { ADA } \\
\text { Mal }\end{array}$} & \multirow{2}{*}{$\begin{array}{c}\text { OPI } \\
\text { Mal }\end{array}$} & \multirow[t]{2}{*}{ GE } \\
\hline & Pak & Mal & Pak & Mal & & & & & & & & \\
\hline PDA & 4.66 & 4.18 & 0.77 & 1.04 & 1 & & & & 1 & & & \\
\hline ADA & 4.32 & 4.22 & 0.68 & 0.93 & $0.49 *$ & 1 & & & $0.84 *$ & 1 & & \\
\hline OPI & 4.40 & 4.21 & 0.77 & 0.91 & 0.44 * & 0.64 * & 1 & & 0.71 * & 0.81 * & 1 & \\
\hline GE & 4.89 & 4.73 & 1.02 & 0.79 & 0.12 * & 0.51 * & 0.53 * & 1 & 0.58 * & 0.29 * & 0.69 * & 1 \\
\hline $\begin{array}{l}\text { Levene Test of } \\
\text { Equality }\end{array}$ & $F=15.9$ & $\mathrm{~F}=3.91$ & $\mathrm{t}=4.91$ & $t=2.10$ & & & & & & & & \\
\hline
\end{tabular}

$* p<0.01$. Pak = Pakistan Mal = Malaysia. PDA = Perception about digital advertising, ADA = Attitude toward digital advertisement, $\mathrm{GE}=$ Gender egalitarianism, and OPI = Online purchase intention .

\subsection{Confirmatory Factor Analysis}

Later, confirmatory factor analysis (CFA) was conducted on AMOS 23.0 separately for the two countries' data (Pakistan and Malaysia) to examine the distinctiveness of all four variables: (a) PDA; (b) ADA; (c) GE; (d) and (d) OPI. The hypothesized six-factor structure with distinct, related factors for PDA, ADA, GE, and OPI was examined separately for both countries' data with several possible models: (a) two unique-factor models-one for each country's data after loading all items on one factor, (b) two models based on two-factor models, by loading all the items of ADA, GE, and OPI on a shared factor instead of the PDA factor, and (c) two four-factor models, by loading all four construct's items on their original factor. Statistics of the composite reliability, Cronbach's alpha, and average variance extracted for each variable are available in Table 2.

The results of the CFA in Table 2 from Pakistan's sample explained that the four-factor model with the item loadings on their original factors PDA, ADA, GE, and OPI showed the finest fit amongst all the alternative models. Similarly, the CFA results in Table 2 from the Malaysian sample described that the four-factor model with the item loadings on their unique factors PDA, ADA, GE, and OPI presented the finest fit amongst all the other models. 
Table 2. Confirmatory factor analysis.

\begin{tabular}{|c|c|c|c|c|c|c|c|}
\hline Model & $\mathrm{x} 2 / \mathrm{df}$ & SRMR & GFI & TLI & IFI & CFI & RMSEA \\
\hline One-factor (Pakistan) & 2.24 & 0.061 & 0.98 & 0.98 & 0.94 & 0.96 & 0.033 \\
\hline Two-factor (Pakistan) & 1.78 & 0.060 & 0.92 & 0.97 & 0.95 & 0.97 & 0.035 \\
\hline Four-factor (Pakistan) & 2.67 & 0.059 & 0.94 & 0.96 & 0.98 & 0.96 & 0.036 \\
\hline One-factor (Malaysia) & 3.71 & 0.059 & 0.93 & 0.95 & 0.97 & 0.95 & 0.040 \\
\hline Two-factor (Malaysia) & 1.34 & 0.060 & 0.91 & 0.94 & 0.95 & 0.98 & 0.051 \\
\hline Four-factor (Malaysia) & 2.45 & 0.058 & 0.97 & 0.93 & 0.96 & 0.93 & 0.048 \\
\hline
\end{tabular}

All items loadings for both countries' data, on their original factors, are significant; the outcomes clarify the consistent factor structure presented in Table 3. Furthermore, the discriminant validity of the PDA, ADA, GE, and OPI construct is within the acceptable range after deleting some items (e.g., two items were deleted from Pakistani data and Malaysian data) and suggests advancing with manipulation check procedure.

Table 3. Discriminant and convergent validity.

\begin{tabular}{|c|c|c|c|c|c|c|c|c|c|c|c|c|c|c|}
\hline \multirow[b]{2}{*}{ Variables } & \multicolumn{2}{|c|}{$\alpha$} & \multicolumn{2}{|c|}{ CR } & \multicolumn{2}{|c|}{ AVE } & \multirow{2}{*}{$\begin{array}{c}\text { PDA } \\
\text { Pak }\end{array}$} & \multirow{2}{*}{$\begin{array}{c}\text { ADA } \\
\text { Pak }\end{array}$} & \multirow{2}{*}{$\begin{array}{l}\text { OPI } \\
\text { Pak }\end{array}$} & \multirow[t]{2}{*}{ GE } & \multirow{2}{*}{$\begin{array}{c}\text { PDA } \\
\text { Mal }\end{array}$} & \multirow{2}{*}{$\begin{array}{c}\text { ADA } \\
\text { Mal }\end{array}$} & \multirow{2}{*}{$\begin{array}{l}\text { OPI } \\
\text { Mal }\end{array}$} & \multirow[t]{2}{*}{ GE } \\
\hline & Pak & Mal & Pak & Mal & Pak & Mal & & & & & & & & \\
\hline PDA & 0.74 & 0.93 & 0.941 & 0.932 & 0.522 & 0.523 & 0.722 & & & & 0.723 & & & \\
\hline ADA & 0.86 & 0.95 & 0.968 & 0.967 & 0.512 & 0.504 & 0.40 * & 0.714 & & & 0.51 * & 0.709 & & \\
\hline OPI & 0.82 & 0.92 & 0.940 & 0.932 & 0.513 & 0.517 & 0.38 * & 0.54 * & 0.716 & & 0.27 * & $0.67^{* *}$ & 0.719 & \\
\hline GE & 0.73 & 0.84 & 0.862 & 0.906 & 0.511 & 0.603 & 0.23 * & 0.41 * & $0.29^{* *}$ & 0.715 & 0.21 * & 0.17 * & 0.62 * & 0.776 \\
\hline
\end{tabular}

${ }^{*} p<0.05 * * p<0.001, \mathrm{CR}=$ Composite reliability, AVE = Average variance extracted, Pak $=$ Pakistan Mal $=$ Malaysia. PDA $=$ Perception about digital advertising, ADA = Attitude toward digital advertisement, GE = Gender egalitarianism, and OPI = Online purchase intention .

\subsection{Manipulation Check}

In the first step, we conducted a one-way repeated measure within-subject ANOVA to examine the manipulation of the PDA within subjects separately for the Pakistani and Malaysian sample between results of the pre-test (without exposure) and post-test (with exposure). A total of 260 participants of experiment 130 from each country was repeatedly measured.

Furthermore, we compared all four groups based on the Malaysian and Pakistani between subject's ANOVA, which revealed a significant mean difference of PDA in between both countries, conditions, and time (M difference PDA pre-test $=1.099 ; p \leq 0.000 ; \mathrm{M}$ difference PDA post-test $=0.473 ; p \leq 0.000$ with $95 \%$ CI). Meanwhile, Levene's test for equality of variances between subjects before the advertisement exposure perception about the PDA also indicated significant $\mathrm{F}(358)=11.32, p \leq 0.001: \mathrm{t}=13.09 ; p \leq 0.000$. Similarly, after the exposure, the results between participants of both countries' PDA remain significantly different as Levene's $\mathrm{F}(358)=15.97, p \leq 0.000: \mathrm{t}=4.91 ; p \leq 0.000$. The between-subject's test revealed significant mean differences of OPI in between both countries regarding conditions and time ( $\mathrm{M}$ difference OPI pre-test $=0.476 ; p \leq 0.000$; $\mathrm{M}$ difference OPI post-test $=0.187 ; p \leq 0.03$ with $95 \% \mathrm{CI}$ ). Meanwhile, Levene's test between subjects before the advertisement exposure about the OPI was also significant $\mathrm{F}$ $(358)=10.09, p \leq 0.926: t=7.19 ; p \leq 0.000$ with a significant $t$ value, indicating that the general perception of the individuals from both countries as the part of Asian cluster was somehow similar, as it was expected. However, after the exposure, the results among the samples of both countries on OPI also found significant Levene's F values (358) $=3.91$, $p \leq 0.43: \mathrm{t}=2.10 ; p \leq 0.03$. Overall, the results showed a significant difference within and between groups. However, the differences based on the within and between analysis are limited; directions of the effect cannot be generalized. Therefore, we used (SEM) for the mediation hypothesis testing. 


\subsection{Testing the Mediation}

We examined the two-mediation model from the sample of two countries based on PDA, ADA, and OPI variables. To verify our hypothesis, SEM was employed. Table 4 illustrates the causal steps techniques as recommended by Baron and Kenny (1986) to analyze the mediation. Primarily, the results (see Figures 2 and 3) explained the direct relations of the PDA, ADA, and OPI variables from Pakistan's data.

Table 4. Mediation of attitude model results.

\begin{tabular}{|c|c|c|c|c|c|c|}
\hline & \multicolumn{3}{|c|}{ Pakistan } & \multicolumn{3}{|c|}{ Malaysia } \\
\hline & $X-Y$ & X-M & M-Y & $X-Y$ & X-M & M-Y \\
\hline Dependent Variables & Y: OPI & M: ADA & Y: OPI & Y: OPI & M: ADA & Y: OPI \\
\hline $\begin{array}{l}\text { Step 1: Independent } \\
\text { Variable PDA }\end{array}$ & $0.27^{* *}(\mathrm{c})$ & $0.49 *(a)$ & $0.17 *\left(c^{\prime}\right)$ & $0.59 *(\mathrm{c})$ & $0.86 *(a)$ & $0.15 *\left(c^{\prime}\right)$ \\
\hline Total Effect & $0.44^{*}$ & - & - & $0.75^{* * *}$ & - & - \\
\hline \multirow{10}{*}{$\begin{array}{c}\mathrm{R}^{2} \\
\text { Step 2: Mediator ADA }\end{array}$} & 0.19 & 0.24 & 0.43 & 0.56 & 0.75 & 0.67 \\
\hline & & & $0.56 *(b)$ & & & $0.69 *(b)$ \\
\hline & & X: PDA & Estimated variance & & $X:$ PDA & Estimated variance \\
\hline & & & $\left(a_{j} b_{j}\right)=0.01$ & & & $\left(a_{j} b_{j}\right)=0.01$ \\
\hline & & & $E\left(a_{j} b_{j}\right)=0.06$ & & & $E\left(a_{j} b_{j}\right)=0.01$ \\
\hline & & & $95 \% \mathrm{CI}=[0.05,0.032]$ & & & $95 \% \mathrm{CI}=[0.01,0.039]$ \\
\hline & & & $\mathrm{SE}=0.05$ & & & $\mathrm{SE}=0.03$ \\
\hline & & & $E\left(a_{j} b_{j}+C\right)=0.27$ & & & $E\left(a_{j} b_{j}+C\right)=0.38$ \\
\hline & & & $95 \% \mathrm{CI}=[0.04,0.031]$ & & & $95 \% \mathrm{CI}=[0.02,0.043]$ \\
\hline & & & $\mathrm{SE}=0.04$ & & & $\mathrm{SE}=0.01$ \\
\hline $\mathrm{R}^{2}$ & & & $0.43\left(c^{\prime}\right)$ & & & $0.67\left(c^{\prime}\right)$ \\
\hline Change $\mathrm{R}^{2}$ & 0.24 & 0.19 & 0.02 & 0.11 & -0.08 & 0.00 \\
\hline Log likelihood & 30 & 28 & 27 & 35 & 48 & 27 \\
\hline AIC & 10.0 & 10.0 & 10.0 & 10.0 & 10.0 & 10.0 \\
\hline $\mathrm{BIC}$ & 18.01 & 18.06 & 18.41 & 15.53 & 18.04 & 20.6 \\
\hline Intercept & $2.35 *$ & $2.31 *$ & $1.27^{*}$ & $1.33^{*}$ & $4.19 *$ & $4.22 *$ \\
\hline
\end{tabular}

Note. The values represent standardized effect, $n=210, n=105$. Entries are random effects with robust standard error. $R 2=$ proportion of variance explained by predictor and mediator; $\mathrm{CI}=$ confidence interval; $\mathrm{AIC}=$ Akaike information criterion; $\mathrm{BIC}=$ Bayesian information criterion. ${ }^{*} p<0.001,{ }^{* *} p<0.01$, and ${ }^{* * *} p<0.02$.

From Pakistan's sample, the positive relation was observed between PDA and OPI as ( $\beta=0.44, p \leq 0.001$ ), and H1a is accepted. Meanwhile, containing the constrained path, we use seven fit indices to evaluate the model fitness, and an acceptable model fitness was produced as follows: $\chi 2=546.52 ; \mathrm{df}=483 ; \chi 2 / \mathrm{df}=1.13 ; p<0.02$; comparative fit index (hereafter CFI) $=0.97$; goodness of fit index (hereafter GFI) $=0.94$; Incremental fit index (hereafter IFI) $=0.98$; Tucker-Lewis Index (hereafter TLI) $=0.97$; standardized root mean square residual (hereafter SRMSR) $=0.059$; and root mean square error of approximation (hereafter RMSEA) $=0.027$; these values were found to be well within the acceptable range and constant with the recommended principles [77,78].

For the mediation of $\mathrm{H} 2 \mathrm{a}$, it was postulated that there is a mediating role of ADA between PDA and OPI among the Pakistani sample, which is also acknowledged as the significant mediated effect of ADA found between PDA and OPI. The relation between PDA and OPI without a mediator was found to be significant $(\beta=0.44, p \leq 0.001$; details are presented in Table 4$)$. In contrast, the direct effect of the mediator between PDA and OPI decreased, but it did not become zero $(\beta=0.17, p \leq 0.01)$, which recommends the partial mediation. 

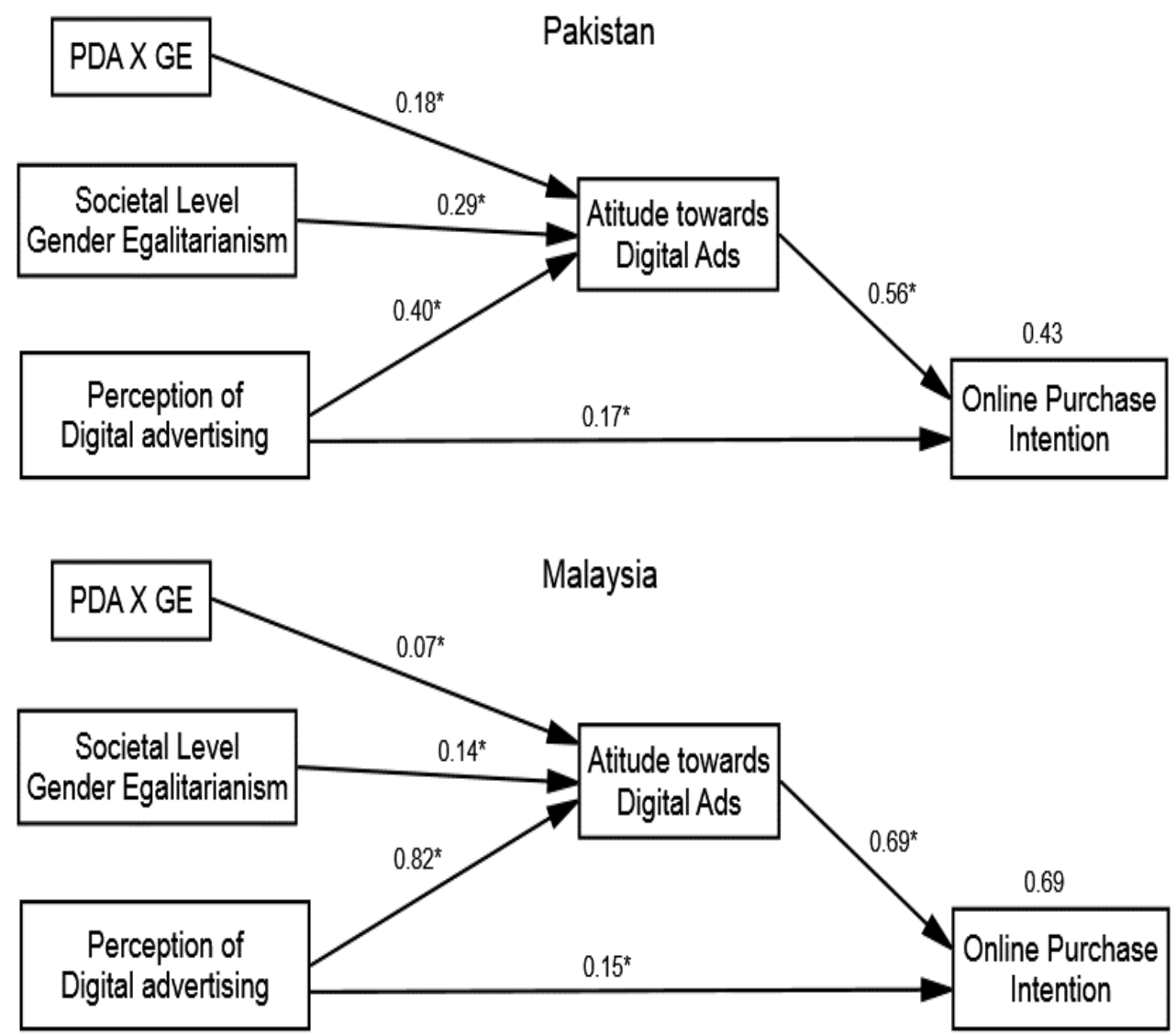

Figure 2. Structural models for gender egalitarianism-moderated mediation of ADA in Pakistan and Malaysia. ${ }^{*} p<0.01$.

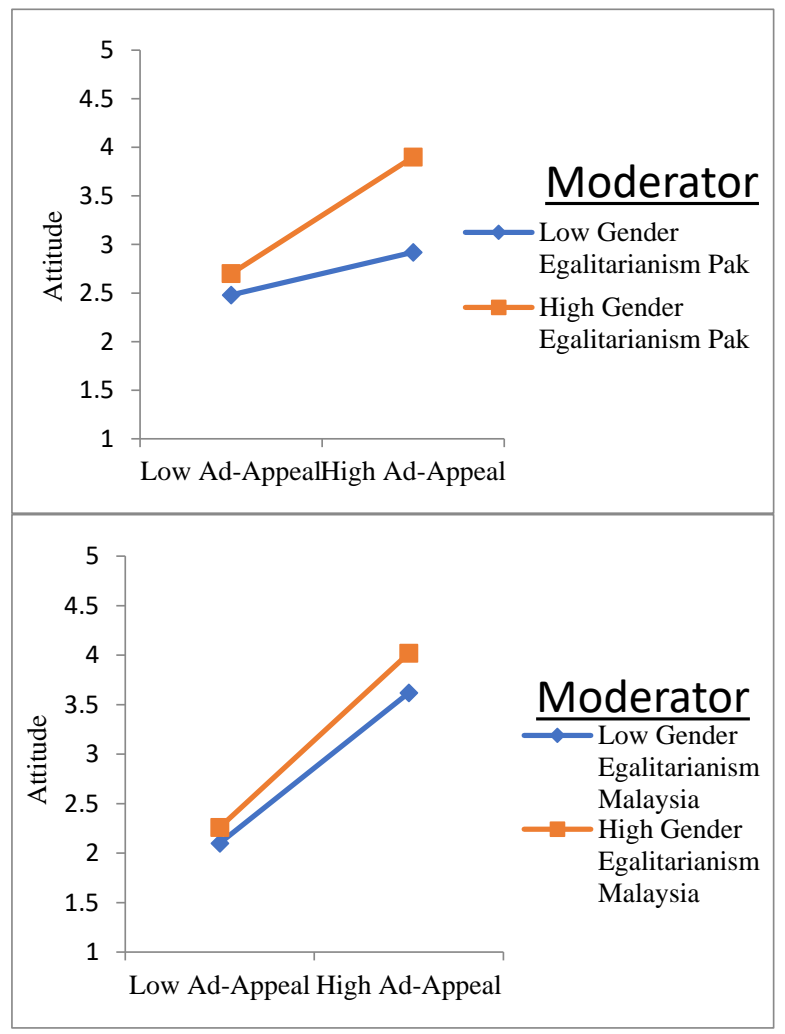

Figure 3. Cross-cultural differences in moderation of gender egalitarianism in Pakistan and Malaysia. 
In the mediation model, $59.4 \%$ of the variance in OPI was estimated due to digital advertising PDA and ADA. The 11 iterations-based bootstrap measure is presented in Table 5 to produce direct, total, and indirect effects. A contrast of the direct and indirect effect and the total effect is presented in Table 4 . The direct effect of PDA on OPI is $(\beta=0.17$, $p \leq 0.01)$ with the total effect of $(\beta=0.44, p \leq 0.001)$, including collective direct and indirect effects. The indirect effect of PDA on OPI was also found significant $(\beta=0.27, p \leq 0.01)$, and the $95 \%$ CI ranged from 0.04 to 0.031 for the unstandardized indirect effect. Therefore, attitude employed a moderate nature of mediation on the relation between PDA and OPI, and $\mathrm{H} 2 \mathrm{a}$ is also approved.

Table 5. Moderation effect of GE on the mediation of ADA model results.

\begin{tabular}{|c|c|c|c|c|}
\hline \multirow[b]{2}{*}{ DV Attitude } & \multicolumn{2}{|c|}{ Pakistan } & \multicolumn{2}{|c|}{ Malaysia } \\
\hline & Model 1 & Model 2 & Model 1 & Model 2 \\
\hline $\begin{array}{c}\text { Step 1: Independent variables } \\
\text { Digital advertising }\end{array}$ & $0.49 *$ & $0.40 *$ & $0.86 *$ & $0.82 *$ \\
\hline Gender egalitarianism & & $0.29 *$ & & $0.14 *$ \\
\hline $\mathrm{R}^{2}$ & 0.24 & 0.26 & 0.75 & 0.73 \\
\hline $\begin{array}{c}\text { Step 2: Moderator } \\
\text { Digital advertising X GE }\end{array}$ & & $0.18 *$ & & $0.07 *$ \\
\hline $\mathrm{R}^{2}$ & & 0.37 & & 0.77 \\
\hline$\Delta \mathrm{R}^{2}$ & & 0.13 & & 0.04 \\
\hline$\Delta \mathrm{R}_{2} \mathrm{ADA}$ in mediation effect on PDA-BI & & 0.08 & & 0.02 \\
\hline
\end{tabular}

Note. $\mathrm{R}^{2}=$ proportion of variance explained by antecedent in both model 1 and $2,{ }^{*} p \leq 0.001$.

The results from the Malaysian sample also suggested that a positive association exists between PDA and OPI as $(\beta=0.75, p=<0.002)$ and approved H1b. Meanwhile, containing the constrained path, we use seven fit indices to evaluate the adequate model fitness, and an acceptable model fitness was attained as follows: $\chi 2=1881.50 ; \mathrm{df}=1361 ; \chi 2 / \mathrm{df}=1.38$; $p<0.04 ; \mathrm{CFI}=0.94 ; \mathrm{GFI}=0.92 ; \mathrm{IFI}=0.94 ; \mathrm{TLI}=0.93 ; \mathrm{SRMSR}=0.058$; and $\mathrm{RMSEA}=0.046$.

For the mediating role of ADA between PDA and OPI among the Malaysian sample, $\mathbf{H} 2 \mathbf{b}$ was hypothesized and is also approved, as there is the substantial mediated effect of AT found between PDA and OPI. The relation between PDA and OPI without a mediator was found to be significant $(\beta=0.75, p \leq 0.001)$; details are presented in Table 4 . Meanwhile, the direct effect with the mediator between PDA and OPI decreased but did not turn to zero and remained significant $(\beta=0.15, p \leq 0.001)$, recommending the partial mediation $[79,80]$.

In the Malaysian sample mediation model, $63.2 \%$ of the variance in OPI was observed by the digital advertising PDA and ADA. The bootstrap procedure was based on the 16 iterations presented in Table 4 to produce direct, total, and indirect effects. Table 5 also illustrates a comparison of the direct, indirect, and total effect of PDA with OPI. The direct effect of PDA on OPI is $(\beta=0.15, \mathrm{~B}=0.14, p \leq 0.001)$ in the mediation model with the total effect of $(\beta=0.75, \mathrm{~B}=0.68, p \leq 0.002)$. The indirect effect of PDA on OPI was also significant $(\beta=0.59, p \leq 0.01)$, with the $95 \%$ CI ranging from 0.02 to 0.043 for the unstandardized indirect effect, and $\mathrm{H} 2 \mathrm{~b}$ is acknowledged. However, the mediation ADA works differently among the Malaysian and Pakistani samples. Therefore, it can be concluded that the ADA partially mediates the relation between PDA and OPI among the Malaysian sample as among the Pakistani sample, but ADA mediates the PDA and OPI relation more strongly among the Malaysians (see Figure 2).

\subsection{Testing the Moderated Mediation}

The interactional effect of cultural dimensions revealed significant changes in the $\mathrm{R}^{2}$ in Table 5 among Pakistan and Malaysia, which were produced by the interactions 
term of GE with PDA, which was found to be within the recommended range for the interactional effect.

It also clarifies the moderating effect on the mediating intensity of ADA on the PDA-OPI link, and it varied according to the function of GE among both nations (see Figure 3). However, the strength and direction were not similar for both nations. For both models' interactional slopes term (PDA X GE), the random effects were examined. The interaction effect of PDA and GE among Pakistanis was ( $\beta=0.18, p<0.001, \mathrm{R} 2=0.37)$, and the change in the mediating effect of the ADA on the PDA-OPI link was $\triangle \mathrm{R} 2=0.13$ (also see Table 5). For the Malaysians, (PDA X GE) was slight ( $\beta=0.07, p<0.001$ ) with $\mathrm{R} 2=0.77$ and surprisingly, it revealed a very slight change in the mediating effect of the ADA on PDA-OPI link, which was $(\Delta R 2=0.02)$. It does not support the H3a and partially supports the H3b. It revealed an interesting fact that digital advertising showing GE is more positively evaluated by the Pakistanis than Malaysians.

\section{Discussion}

Perhaps, these hypotheses also contribute to a better explanation of the digital advertising outcome to predict the intention to online purchase a clothing brand through testing the understudied antecedents and moderating factors. Our conceptual model also advances the advertising influence theory and TPB model by adding novel influencing factors such as GE on the attitude, which would improve the cultural description of this theory. By doing so, it also responds to the recent research [81] to revisit the notion of the norm, which remains the weakest and most inconsistent predictor in the TPB model. To observe the directions of hypothesized effects and objective of this study, structural equation modeling (SEM) has been used. The SEM has been employed for twofold objectives: for validation of the proposed model and examination of the hypothesis, which has resulted in answering the research questions. This SEM has briefly revealed that advertising appeals employed in the digital advertisement to promote clothing brands have a statically significant but diverse effect on the OPI across cultures. In testing the hypothesis related to GE, the analysis has shown contrary findings. By looking into the high score of Malaysia on GE practices, it was hypothesized that equality of status would be more valued by the Malaysians than Pakistanis, but it was not the same case. This has also been observed in a recent study [35] that used GLOBE gender egalitarian and found a contrary association between GE values and practices [46]. In addition, it has been suggested that Malaysians are more inclined toward advertising appeals while making decisions on using clothing brands.

Our moderated mediation results are consistent with these recommendations and proved that cultural congruence can be considered while practicing digital advertising. However, both samples have demonstrated a moderate nature of the interactional effect. This is consistent with the past studies that identified cultural influence in defining the advertising in effectiveness [35,46,82]. Another explanation of these results is grounded in cultural theories that an individual socialized in a culture with high GE might perceive a given advertisement appeal as expressively less GE than an individual socialized in a relatively less GE culture [21].

\subsection{Theoretical Implications}

This study contributes to cross-cultural advertising and strategic communication practices, which presently are under theoretical debate in the body of knowledge and still growing. Indeed, the experimental study offers norm congruence-centered mediation of attitude implications. Considering two culturally diverse Muslim nations helps to clarify the cultural positioning of both the nations and the general misunderstanding of the perceiving religious similarities as the standard tool for advertising practices. Our consideration of the norm-centered approach contributed to the literature by identifying that attitude norms congruence serves as a fundamental implication of interpreting advertising messages and OPI. In addition, using conceptually diverse constructs of digital advertising, attitude, and intention offer a more detailed elaboration of the factors involved in their relation. 
There are several contributions of our study to the cross-cultural advertising and communication literature. First, although the position of the antecedents of the TPB in predicting the intention has been described in prior studies [81], however, there was still a need to address this gap in the norm congruence context. For example, studies indicated that there are many rationales of diversity in the prediction of the OPI on the position of certain factors affecting the attitude, which strengthen the postulation that attitude mediates the OPI and digital advertising. Our study also found that ADA is positively affected by the advertising content and its exposure regarding developing the intention toward advertising. The results are based on the experimental evidence to clarify the position of the attitude, which is an antecedent in the TPB model to predict intention. The results revealed that advertising is significantly related to attitude, and one of the crucial factors remains detached from the attitude to predict the intention.

Secondly, this study contributes further by addressing the attitude norm congruence mediating implications through consideration of the advertising interpretations and linking it with the intended outcome. The consideration of the cultural norms-guided interpretation of the advertising diversifies the implications of the study. In addition, the study provides the diverse context to measure facades closely related to the societal influences on the individuals. For example, we consider the scale for measuring OPI with the features such as the sense of societal factors that individuals can attribute to in the message used in the digital advertising or its display by using its cultural information. Furthermore, by confirming through the experimental design, the individuals were provided with the practical stimuli to respond to their evaluation of the digital advertising. Therefore, the intended outcomes of our findings are conceptually diverse and grounded on the norms of congruence digital advertising evaluation and provide a more promising way for future investigations. In testing the hypothesis related to GE, the analysis has shown contrary findings. By looking into the high score of Malaysia on GE practices, it was hypothesized that equality of status would be more valued by the Malaysians than Pakistanis, but it was not the same case. This has been also observed in a recent study [35] that used GLOBE gender egalitarian and found such a contrary association between GE values and practices.

Thirdly, our investigation exposed some astonishing and practically appropriate outcomes: the Pakistani sample reveals a more positive intention to use clothing brands when receiving the GE in digital advertising. However, cultural congruence remains crucial for the attitude-driven intentions in both nations. By doing so, these findings add new information to the international advertising theory, in which the salient feature of nation remains significant.

Finally, the cross-cultural evaluation of the individual's evaluation of digital advertising from two nations, Malaysia and Pakistan, provides more understanding about the importance of the cultural context. The results help understanding of how individuals learn and respond differently from their culture. For example, the relation of the attitude and appeals were found to be stronger among Malaysians than Pakistanis. This suggests that Malaysians are more sensitive toward the meanings of the advertising message and significantly different from Pakistanis to perceive digital advertising. Similarly, the findings provide evidence that intention outcome among the Malaysians was also found to be more significantly mediated through attitude.

\subsection{Implications for Practices}

The findings indicate that advertisers in the future may consider norm-congruent advertising appeals while designing digital advertising. The findings suggest that two Muslim nations, Pakistan and Malaysia, which are generally assumed as similar enough to practice the commonly standardized digital advertising, is not a workable strategy. There is a need to consider the cultural perspective of the individuals deeply rooted in the national culture. For an effective digital advertising strategy, it is crucial to understand the importance of the nation's culture. In a nutshell, deliberations must be made about the desired cultural orientations such as GE. Advertising culturally manifested cues that are 
closer or matched with the consumer's nation cultural orientation can provide benefits to the digital advertisers in terms of attraction as well as evoke positive evaluations leading toward an increase in sales.

\subsection{Limitations and Directions for Future Research}

We used the experimental method to evaluate the GE and ADA-moderated mediated implications of the cause and effect model of the PDA and OPI, as the survey-oriented studies lack explanatory power. However, one limitation is the use of a student sample; regardless of its homogeneity, to ensure more reliable results, future studies may consider a sample of another nature. Still, limitations are there in terms of the scope; future studies may consider samples from some western and eastern countries for a more detailed analysis of the normative-centered mediating role of the attitude by using the same model. The study uses a single product category of clothing brands; future studies can underpin multiple fashion brands. Finally, future studies can also compare different product categories to establish the self-affirmative role of value congruency advertising practices.

\section{Conclusions}

The current research clarified the role of cultural value congruity significance in designing digital advertising. The implications appear that overall, gender equality had been perceived positively by individuals of both nations. The intensity reflects that cultures such as Malaysia practicing more gender equality have strong intentions as a result of the exposure to GE in an advertisement. On the other hand, the Pakistani GE appeal is also deciphered into a preference for advertisement, which incorporates GE appeals and equates with the cultural tendency of GE. Overall, findings validated the assumption of SAP that the attraction of value congruity in fact encourages the individuals' positive evaluation of the product that matches their GE values across both nations. Therefore, the advertisers must focus on the adaption strategy by assimilating the congruent values in digital advertising.

Author Contributions: Conceptualization: S.H.R. and U.Z.; methodology: S.H.R. and U.Z.; software: S.H.R.; validation: S.H.R.; formal analysis: S.H.R.; investigation: S.H.R. and U.Z.; resources: S.H.R. and U.Z.; data curation: S.H.R. and U.Z.; writing-original draft preparation: S.H.R. and U.Z.; writing-review and editing: S.H.R. and U.Z.; project administration: U.Z. All authors have read and agreed to the published version of the manuscript.

Funding: This research received no external funding.

Institutional Review Board Statement: The study was conducted according to the guidelines of the Declaration of Helsinki and approved by the Institutional Research Ethical Committee of Bahauddin Zakariya University, Multan 66000, Pakistan, and approval Number. TMA/2020.

Informed Consent Statement: Informed consent was obtained from all subjects involved in the study.

Data Availability Statement: The data that support the findings of this study are available from the corresponding author upon reasonable request due to ethical and privacy restrictions.

Conflicts of Interest: The authors declare no conflict of interest.

\section{References}

1. Westjohn, S.A.; Singh, N.; Magnusson, P. Responsiveness to Global and Local Consumer Culture Positioning: A Personality and Collective Identity Perspective. J. Int. Mark. 2012, 20, 58-73. [CrossRef]

2. Hornik, J.; Ofir, C.; Rachamim, M. Advertising Appeals, Moderators, And Impact on Persuasion. J. Advert. Res. 2017, 57, 305-318. [CrossRef]

3. De Mooij, M. On the misuse and misinterpretation of dimensions of national culture. Int. Mark. Rev. 2013, 30, 253-261. [CrossRef]

4. Lee, H.; Cho, C.-H. Digital advertising: Present and future prospects. Int. J. Advert. 2020, 39, 332-341. [CrossRef]

5. Scott, L. Advertising and Advertisements. Int. Encycl. Soc. Behav. Sci. 2015, 2015, 194-200. [CrossRef]

6. Samiee, S.; Jeong, I.; Pae, J.H.; Tai, S. Advertising standardization in multinational corporations. J. Bus. Res. 2003, 56, 613-626. [CrossRef] 
7. Gordon, B.R.; Jerath, K.; Katona, Z.; Narayanan, S.; Shin, J.; Wilbur, K.C. Inefficiencies in Digital Advertising Markets. J. Mark. 2021, 85, 7-25. [CrossRef]

8. Saura, J.R. Using Data Sciences in Digital Marketing: Framework, methods, and performance metrics. J. Innov. Knowl. 2020. [CrossRef]

9. Zaman, U.; Abbasi, M. Linking transformational leadership and individual learning behavior: Role of psychological safety and uncertainty avoidance. Pakistan J. Commer. Soc. Sci. 2020, 14, 167-201.

10. Mensa, M.; Bittner, V. Portraits of Women: Mexican and Chilean Stereotypes in Digital Advertising. Commun. Soc. 2020, 33, 63-78. [CrossRef]

11. Paek, H.-J.; Nelson, M.R.; Vilela, A.M. Examination of Gender-role Portrayals in Television Advertising across Seven Countries. Sex Roles 2010, 64, 192-207. [CrossRef]

12. Zawisza, M.; Luyt, R.; Zawadzka, A.M.; Buczny, J. Cross-Cultural Sexism and the Effectiveness of Gender (Non)Traditional Advertising: A Comparison of Purchase Intentions in Poland, South Africa, and the United Kingdom. Sex Roles 2018, 79, 738-751. [CrossRef]

13. Chin, S.; Wilson, B.; Russo, A. Advances in Advertising Research (Vol. IV). Adv. Advert. Res. 2013, 4, 73-85. [CrossRef]

14. Mäntymäki, M.; Merikivi, J.; Verhagen, T.; Feldberg, J.; Rajala, R. Does a contextualized theory of planned behavior explain why teenagers stay in virtual worlds? Int. J. Inf. Manag. 2014, 34, 567-576. [CrossRef]

15. Gramazio, S.; Cadinu, M.; Guizzo, F. Does Sex Really Sell? Paradoxical Effects of Sexualization in Advertising on Product Attractiveness and Purchase Intentions. Sex Roles 2020, 84, 1-19. [CrossRef]

16. Zawisza, M.; Luyt, R.; Zawadzka, A.M.; Buczny, J. Does it pay to break male gender stereotypes in advertising? A comparison of advertisement effectiveness between the United Kingdom, Poland and South Africa. J. Gend. Stud. 2016, 27, 464-480. [CrossRef]

17. Grau, S.L.; Zotos, Y.C. Gender stereotypes in advertising: A review of current research. Int. J. Advert. 2016, 35, 761-770. [CrossRef]

18. Akhter, W.; Abassi, A.S.; Umar, S. Ethical issues in advertising in pakistan: An islamic perspective. World Appl. Sci. J. 2011, 13, 444-452.

19. Ali, A. Gender Role Portrayal in Television Advertisement: Evidence from Pakistan. Inf. Manag. Bus. Rev. 2012, 4, 340-351. [CrossRef]

20. Hong, Y.H.; Soh, C.H.; Khan, N.; Bin Abdullah, M.M.; Teh, B.H. Effectiveness of Anti-Smoking Advertising: The Roles of Message and Media. Int. J. Bus. Manag. 2013, 8. [CrossRef]

21. Czarnecka, B.; Brennan, D.; Keles, S. Cultural Meaning, Advertising, and National Culture: A Four-Country Study. J. Glob. Mark. 2017, 31, 4-17. [CrossRef]

22. Raza, S.H.; Iftikhar, M.; Mohamad, B.; Pembecioğlu, N.; Altaf, M. Precautionary Behavior Toward Dengue Virus Through Public Service Advertisement: Mediation of the Individual's Attention, Information Surveillance, and Elaboration. SAGE Open 2020, 10, 2158244020929301. [CrossRef]

23. Webb, D.; Kohlbacher, F.; Prieler, M. Life satisfaction in Japan: The role of hedonic values, advertising and watching TV. Soc. Bus. 2017, 7, 155-175. [CrossRef]

24. Prieler, M.; Kohlbacher, F.; Hagiwara, S.; Arima, A. Gender Portrayals of Older People in Japanese Television Advertisements. J. Asian Women 2017, 33, 25. [CrossRef]

25. Prieler, M.; Kohlbacher, F. Advertising in the Aging Society: Understanding Representations, Practitioners, and Consumers in Japan; Palgrave Macmillan: London, UK, 2016. [CrossRef]

26. Zawisza-Riley, M. Advertising, culture and society. Advert. Gend. Soc. 2019, 2019, 3-16. [CrossRef]

27. Pagani, M.; Goldsmith, R.; Perracchio, A. Standardization vs. adaptation: Consumer reaction to TV ads containing subtitled or English dubbed ads. Int. J. Advert. 2015, 34, 702-714. [CrossRef]

28. Bekk, M.; Spörrle, M.; Völckner, F.; Spieß, E.; Woschée, R. What is not beautiful should match: How attractiveness similarity affects consumer responses to advertising. Mark. Lett. 2017, 28, 509-522. [CrossRef]

29. Liaukonyte, J.; Teixeira, T.; Wilbur, K.C. Television Advertising and Online Shopping. Mark. Sci. 2015, 34, 311-330. [CrossRef]

30. Schivinski, B.; Dabrowski, D. The effect of social media communication on consumer perceptions of brands. J. Mark. Commun. 2013, 22, 189-214. [CrossRef]

31. O'Cass, A.; Lee, W.J.; Siahtiri, V. Can Islam and status consumption live together in the house of fashion clothing? J. Fash. Mark. Manag. Int. J. 2013, 17, 440-459. [CrossRef]

32. House, R.J.; Quigley, N.R.; De Luque, M.S. Insights from Project GLOBE. Int. J. Advert. 2010, 29, 111-139. [CrossRef]

33. McLellan, R. Culture and leadership. Quarr. Manag. 2002, 29, 15. [CrossRef]

34. Ajzen, I. The theory of planned behaviour: Reactions and reflections. Psychol. Health 2011, 26, 1113-1127. [CrossRef] [PubMed]

35. Diehl, S.; Terlutter, R.; Mueller, B. Doing good matters to consumers: The effectiveness of humane-oriented CSR appeals in cross-cultural standardized advertising campaigns. Int. J. Advert. 2016, 35, 730-757. [CrossRef]

36. Gazley, A.; Krisjanous, J.; Grohs, R.; Fam, K.-S. Like it or not: Differences in advertising likeability and dislikeability within Asia. Asia Pac. J. Mark. Logist. 2012, 24, 23-40. [CrossRef]

37. Khairullah, D.Z.; Khairullah, Z.Y. Cultural Values in Indian Television Advertising. J. Promot. Manag. 2013, 19, 265-281. [CrossRef]

38. Hornikx, J.; De Groot, E. Cultural values adapted to individualism-collectivism in advertising in Western Europe: An experimental and meta-analytical approach. Int. Commun. Gaz. 2017, 79, 298-316. [CrossRef] 
39. Abu Bakar, H.; Bahtiar, M.; Halim, H.; Subramaniam, C.; Choo, L.S. Shared Cultural Characteristics Similarities in Malaysia's Multi-ethnic Society. J. Intercult. Commun. Res. 2018, 47, 243-267. [CrossRef]

40. Van Herk, H.; Torelli, C.J. Cross Cultural Issues in Consumer Science and Consumer Psychology: Current Perspectives and Future Directions; Springer: Cham, Switzerland, 2017. [CrossRef]

41. Raza, S.; Zaman, U.; Iftikhar, M.; Shafique, O. An Experimental Evidence on Eco-Friendly Advertisement Appeals and Intention to Use Bio-Nanomaterial Plastics: Institutional Collectivism and Performance Orientation as Moderators. Int. J. Environ. Res. Public Health 2021, 18, 791. [CrossRef] [PubMed]

42. Maseland, R.; Van Hoorn, A. Culture at the Country Level. In Cross Cultural Issues in Consumer Science and Consumer Psychology; Springer: Cham, Switzerland, 2017; pp. 7-32. [CrossRef]

43. De Mooij, M. Cross-cultural research in international marketing: Clearing up some of the confusion. Int. Mark. Rev. 2015, 32, 646-662. [CrossRef]

44. House, R.J.; Hanges, P.J.; Javidan, M.; Dorfman, P.W.; Gupta, V. Culture, Leadership, and Organizations; The GLOBE Study of 62 Societies-SAGE Publications, Inc.: New York, NY, USA, 2004.

45. Abu Bakar, H.; McCann, R.M. Workgroup diversity: Surface-level actual similarity and deep-level perceived similarity in leader-member relationship communication. Corp. Commun. Int. J. 2018, 23, 35-50. [CrossRef]

46. Raza, S.H.; Abu Bakar, H.; Mohamad, B. The effects of advertising appeals on consumers' behavioural intention towards global brands. J. Islam. Mark. 2019, 11, 440-460. [CrossRef]

47. Merkin, R. Pakistani Cultural Characteristics: Updated VSM Scores and Facework Geared towards Increasing Women's Access to Education. Commun. Differ. 2016, 2016, 168-181. [CrossRef]

48. Hussain, R. The effect of religious, cultural and social identity on population genetic structure among Muslims in Pakistan. Ann. Hum. Biol. 2005, 32, 145-153. [CrossRef] [PubMed]

49. Majid, A. Cultural influence in Advertising Advertisements in Sweden and Pakistan. Univ. Gothenbg. 2013, 4, 1-52.

50. Kim, S.; Jeong, S.-H.; Hwang, Y. Why are there cross-national differences in response to comparative advertising?: Some mediators. J. Mark. Commun. 2016, 24, 569-587. [CrossRef]

51. Romberg, A.R.; Bennett, M.; Tulsiani, S.; Simard, B.; Kreslake, J.M.; Favatas, D.; Vallone, D.M.; Hair, E.C. Validating Self-Reported Ad Recall as a Measure of Exposure to Digital Advertising: An Exploratory Analysis Using Ad Tracking Methodology. Int. J. Environ. Res. Public Health 2020, 17, 2185. [CrossRef]

52. Munsch, A. Millennial and generation $\mathrm{Z}$ digital marketing communication and advertising effectiveness: A qualitative exploration. J. Glob. Sch. Mark. Sci. 2021, 31, 10-29. [CrossRef]

53. Nguyen, H. Advertising Appeals and Cultural Values in Social Media Commercials in UK, Brasil and India: Case Study of Nokia and Samsung. Int. J. Soc. Behav. Educ. Econ. Bus Ind. Eng. 2014, 8, 2406-2414.

54. Smith, K.T. Digital marketing strategies that Millennials find appealing, motivating, or just annoying. J. Strat. Mark. 2011, 19, 489-499. [CrossRef]

55. Raza, S.H.; Adamu, A.A.; Ogadimma, E.C.; Hasnain, A. The Influences of Political Values Manifested in Advertisements on Political Participation: Moderating Roles of Self-transcendence and Conservation. J. Creative Commun. 2020, 15, 318-341. [CrossRef]

56. Wong, C.-H.; Tan, G.W.-H.; Tan, B.-I.; Ooi, K.-B. Mobile advertising: The changing landscape of the advertising industry. Telemat. Inform. 2015, 32, 720-734. [CrossRef]

57. Huang, J.; Su, S.; Zhou, L.; Liu, X. Attitude Toward the Viral Ad: Expanding Traditional Advertising Models to Interactive Advertising. J. Interact. Mark. 2013, 27, 36-46. [CrossRef]

58. Okazaki, S.; Mueller, B.; Taylor, C.R. Measuring soft-sell versus hard-sell advertising appeals. J Advert. 2010, 39, 5-20. [CrossRef]

59. Bergkvist, L.; Langner, T. Construct Measurement in Advertising Research. J. Advert. 2017, 46, 129-140. [CrossRef]

60. Terlutter, R.; Diehl, S.; Mueller, B. The GLOBE study-Applicability of a new typology of cultural dimensions for cross-cultural marketing and advertising research. Int. Advert. Commun. 2006, 2006, 419-438. [CrossRef]

61. Lu, L.-C.; Chang, W.-P.; Chang, H.-H. Consumer attitudes toward blogger's sponsored recommendations and purchase intention: The effect of sponsorship type, product type, and brand awareness. Comput. Hum. Behav. 2014, 34, 258-266. [CrossRef]

62. Raza, S.H.; Abu Bakar, H.; Mohamad, B. Relationships between the advertising appeal and behavioral intention: The mediating role of the attitude towards advertising appeal and moderating role of cultural norm. J. Bus. Retail. Manag. Res. 2018, 12, 185-193. [CrossRef]

63. Lee, J.; Hong, I.B. Predicting positive user responses to social media advertising: The roles of emotional appeal, informativeness, and creativity. Int. J. Inf. Manag. 2016, 36, 360-373. [CrossRef]

64. Zeng, F.; Huang, L.; Dou, W. Social Factors in User Perceptions and Responses to Advertising in Online Social Networking Communities. J. Interact. Advert. 2009, 10, 1-13. [CrossRef]

65. Chu, S.-C.; Kamal, S.; Kim, Y. Understanding consumers' responses toward social media advertising and purchase intention toward luxury products. J. Glob. Fash. Mark. 2013, 4, 158-174. [CrossRef]

66. Jai, T.-M.; Burns, L.D.; King, N.J. The effect of behavioral tracking practices on consumers' shopping evaluations and repurchase intention toward trusted online retailers. Comput. Hum. Behav. 2013, 29, 901-909. [CrossRef]

67. Bright, L.F.; Daugherty, T. Does customization impact advertising effectiveness? An exploratory study of consumer perceptions of advertising in customized online environments. J. Mark. Commun. 2012, 18, 19-37. [CrossRef] 
68. Brewer, P.; Venaik, S. Individualism-Collectivism in Hofstede and GLOBE. J. Int. Bus. Stud. 2011, 42, 436-445. [CrossRef]

69. Tran, T.P. Personalized ads on Facebook: An effective marketing tool for online marketers. J. Retail. Consum. Serv. 2017, 39, 230-242. [CrossRef]

70. Okazaki, S.; Taylor, C.R. Social media and international advertising: Theoretical challenges and future directions. Int. Mark. Rev. 2013, 30, 56-71. [CrossRef]

71. Taylor, C.R.; Okazaki, S. Do Global Brands Use Similar Executional Styles Across Cultures? A Comparison of U.S. and Japanese Television Advertising. J. Advert. 2015, 44, 276-288. [CrossRef]

72. House, R.; Javidan, M.; Hanges, P.; Dorfman, P. Understanding cultures and implicit leadership theories across the globe: An introduction to project GLOBE. J. World Bus. 2002, 37, 3-10. [CrossRef]

73. Raza, S.H.; Abu Bakar, H.; Bin Mohamad, B. Advertising appeals and Malaysian culture norms. J. Asian Pac. Commun. 2018, 28, 61-82. [CrossRef]

74. Ducoffe, R.H. How Consumers Assess the Value of Advertising. J. Curr. Issues Res. Advert. 1995, 17, 1-18. [CrossRef]

75. Lim, J.S.; Ri, S.Y.; Egan, B.D.; Biocca, F.A. The cross-platform synergies of digital video advertising: Implications for cross-media campaigns in television, Internet and mobile TV. Comput. Hum. Behav. 2015, 48, 463-472. [CrossRef]

76. Sari, D.; Kusuma, B. Does Luxury Brand Perception Matter In Purchase Intention? A Comparison Between A Japanese Brand And A German Brand. ASEAN Mark. J. 2014, 6, 50-63. [CrossRef]

77. Zaman, U.; Nadeem, R.D.; Nawaz, S.; Ardito, L. Cross-country evidence on project portfolio success in the Asia-Pacific region: Role of CEO transformational leadership, portfolio governance and strategic innovation orientation. Cogent Bus. Manag. $2020,7$. [CrossRef]

78. Zaman, U.; Jabbar, Z.; Nawaz, S.; Abbas, M. Understanding the soft side of software projects: An empirical study on the interactive effects of social skills and political skills on complexity-performance relationship. Int. J. Proj. Manag. 2019, 37, 444-460. [CrossRef]

79. Baron, R.M.; Kenny, D.A. The moderator-mediator variable distinction in social psychological research: Conceptual, strategic, and statistical considerations. J. Pers. Soc. Psychol. 1986, 51, 1173-1182. [CrossRef] [PubMed]

80. Hayes, A.F. Beyond Baron and Kenny: Statistical Mediation Analysis in the New Millennium. Commun. Monogr. 2009, 76, 408-420. [CrossRef]

81. Sniehotta, F.F.; Presseau, J.; Araújo-Soares, V. Time to retire the theory of planned behaviour. Health Psychol. Rev. 2014, 8, 1-7. [CrossRef]

82. Meuller, B.; Diehl, S.; Terlutter, R. GLOBE Cultural Dimensions: Providing Insight for advertising Execuation in the Global Marketplace. Adv. Advert. Res. 2015, 5, 73-85. [CrossRef] 